\title{
Participation in structured programming may prevent unhealthy weight gain during the summer in school-aged children from low-income neighbourhoods: feasibility, fidelity and preliminary efficacy findings from the Camp NERF study
}

\author{
Laura C Hopkins ${ }^{1,2}$, Christopher Holloman ${ }^{3}$, Bernadette Melnyk ${ }^{4}$, Mary Fristad ${ }^{5}$, \\ Jacqueline D Goodway ${ }^{1}$, Julie A Kennel ${ }^{1}$, Ihuoma Eneli ${ }^{6}$ and Carolyn Gunther 1,2,7,* \\ 'Department of Human Sciences, The Ohio State University, 313 Campbell Hall, 1787 Neil Avenue, Columbus, \\ $\mathrm{OH} 43210$, USA: ${ }^{2}$ Department of Family and Consumer Sciences, Office of Extension, The Ohio State University, \\ Columbus, OH, USA: ${ }^{3}$ Department of Statistics, The Ohio State University, Columbus, OH, USA: ${ }^{4}$ College of \\ Nursing, The Ohio State University, Columbus, OH, USA: ${ }^{5}$ Department of Psychiatry and Behavioral Health, \\ The Ohio State University, Columbus, OH, USA: ${ }^{\circ}$ Nationwide Children's Hospital Center for Healthy Weight and \\ Nutrition, Columbus, OH, USA: ${ }^{7}$ Department of Pediatrics, College of Medicine, The Ohio State University, \\ Columbus, $\mathrm{OH}, \mathrm{USA}$
}

Submitted 26 July 2018: Final revision received 11 October 2018: Accepted 29 October 2018: First published online 3 January 2019

\begin{abstract}
Objective: Evaluate the feasibility, fidelity and preliminary efficacy of Camp NERF to prevent unhealthy weight gain and promote healthy behaviours in children during the summer.

Design: Camp NERF was an 8-week, multicomponent, theory-based programme coupled with the US Department of Agriculture's Summer Food Service Program. Twelve eligible elementary-school sites were randomized to one of three treatment groups: (i) Active Control (non-nutrition, -physical activity (PA), -mental health); (ii) Standard Care (nutrition and PA); or (iii) Enhanced Care (nutrition and PA, plus cognitive behavioural techniques) programming. Efficacy was determined by assessing mean change by group in child outcomes using hierarchical linear regression models.

Setting: Low-income, urban neighbourhoods in Columbus, OH, USA.

Participants: Economically disadvantaged, racial minority children of elementary school age (kindergarten-5th grade).

Results: Eighty-seven child-caregiver dyads consented; eighty-one completed preand post-intervention assessments resulting in a $93.10 \%$ retention rate. Delivery of the intended lesson occurred $79-90 \%$ of the time. Of the children, $56.98 \%(n$ 49) were female; $89.53 \%$ ( $n$ 77) were Black. Overall mean change in BMI $Z$-score from baseline to post-intervention was -0.03 (SE 0.05); change in BMI $Z$-score did not differ significantly between treatment group. Change in nutrition, PA, mental health or psychosocial outcomes did not differ between groups.

Conclusions: Results from the current study demonstrate feasibility and fidelity, yet no intervention effect of Camp NERF. Instead, findings suggest that participation in structured programming of any type (health behaviour-related or not) may prevent unhealthy summer weight gain. Additional studies are needed to confirm findings. Results have implications for child nutrition policy addressing the issue of summer health.
\end{abstract}

While recent reports indicate a plateau in US childhood obesity rates, the number of obese children remains high $^{(1-3)}$. In 2015-2016, obesity affected $18.5 \%$ of US youth $^{(3)}$. This is concerning due to the devastating consequences on children's physical and mental health and academic success ${ }^{(2,4,5)}$. Troubling data indicate that school-aged children experience unhealthy gains in BMI at a rate nearly twice as fast during the summer months when school is out of session compared with the school year ${ }^{(2,6-12)}$. African-American and Hispanic minority 
groups, sub-populations already at increased risk for obesity, as well as girls, may be particularly vulnerable to unhealthy weight gain during these non-academic months ${ }^{(1,2)}$.

Schools play a critical role in promoting healthy diet and physical activity behaviours during the academic year ${ }^{(2,13)}$. There is a belief that the loss of access to the structure of the school environment may in part explain unhealthy summer weight gain (i.e. provision of healthy snacks and meals; opportunity for structured and unstructured physical activity; nutrition-, physical activity- and health-related policies and programmes) ${ }^{(14)}$. The US Department of Agriculture's (USDA) food security net, specifically the Summer Food Service Program (SFSP), is intended to address this problem by providing access to nutritious meals to children during the summer when school is out of session $^{(2,15)}$. Unfortunately, attendance at USDA SFSP sites, particularly open $v$. closed sites in which the site is 'open' to all children aged $<18$ years old and enrolment is not required, and amount of meals served are low relative to school-based nutrition programmes ${ }^{(2)}$. According to the Food Research Action Center, only one of seven free or reduced-cost school lunch participants in the 2015-2016 school year received lunch in the summer of 2016 nationally $^{(16)}$. In Ohio, only $10 \cdot 1 \%$ of free or reduced-cost school lunch participants participated in the $\mathrm{SFSP}^{(16)}$. Stakeholders hypothesize that these low numbers are due in large part to a lack of age-appropriate and engaging structured programming at sites to attract children ${ }^{(2)}$.

Unfortunately, few efforts have been invested in designing and testing evidence-informed nutrition and physical activity programmes that may be delivered in companion with the USDA SFSP to provide underserved children with the resources to prevent excess weight gain during the summer recess ${ }^{(2)}$. The main objective of the present study was to determine the impact of Camp Nutrition Education Recreation and Fitness (Camp NERF), a multicomponent nutrition, physical activity and mental health intervention coupled with USDA SFSP open sites, on child behavioural health and anthropometric outcomes. Specifically, the aims and hypotheses were to:

1. Evaluate feasibility and fidelity outcomes of Camp NERF. Hypothesis 1: Camp NERF will demonstrate high feasibility (retention, attendance and satisfaction) and fidelity (implementation, engagement) with child participants.

2. Evaluate the efficacy of Camp NERF to improve child anthropometric outcomes. Hypothesis 2: BMI $Z$-scores will improve more from baseline to post-intervention among children participating at the Enhanced Care sites compared with Standard Care and Active Control sites.

3. Evaluate the efficacy of Camp NERF to improve child nutrition, physical activity, mental health and psychosocial outcomes. Hypothesis 3: Fruit and vegetable preferences, snack preferences, diet quality, physical activity, self-concept, and social support for healthy and unhealthy eating will improve more from baseline to post-intervention among children participating at Enhanced Care sites compared with Standard Care and Active Control sites.

\section{Methods}

\section{Research design}

Camp NERF was a multicomponent nutrition, physical activity and mental health intervention coupled to the USDA SFSP, specifically open sites located at public elementary schools (twelve were recruited). It was an 8-week pre-test/post-test group (site) randomized controlled trial. Through daily access to healthy foods, safe play and structured physical activity, along with engagement in an evidence-informed health behaviour educational curriculum, Camp NERF was designed to prevent unhealthy weight gain during summer months in school-aged children. Potential sites were identified by a community partner whose responsibility is to support SFSP sites in Franklin County, Ohio, and were considered eligible if they were: (i) an elementary school; (ii) a USDA SFSP open site; and (iii) lacking structured programming. Twelve sites were identified as meeting these criteria and randomized to one of three treatment or programming groups: (i) Active Control (non-nutrition, -physical activity or -mental health 4-H programming); (ii) Standard Care (nutrition and physical activity programming); and (iii) Enhanced Care (nutrition, physical activity and mental health (i.e. cognitive behavioural techniques) programming). Additional information regarding the Camp NERF intervention research design and methods has been published elsewhere ${ }^{(2)}$.

\section{Participants and recruitment}

The Camp NERF target population was low-income, racial minority children entering kindergarten through 5 th grade and their primary adult caregiver from urban neighbourhoods in Columbus, Ohio. Participants were recruited through various methods including school announcements, emails, flyers, phone calls and neighbourhood canvassing. Prior to study enrolment, a caregiver consent form, caregiver permission form and child assent form were completed by participants. Participants received gift card incentives at baseline and post-intervention for their participation in the study.

\section{Data collection}

\section{Data collector training}

Data collectors were undergraduate and graduate students from nutrition, public health or other related fields, and 
registered dietitian nutritionists. All data collectors underwent an $8 \mathrm{~h}$ data collector training, which included didactic sessions followed by role-playing to practice techniques and become familiar with the instruments. Toward the end of the 8 -week intervention, prior to posttest data collection, data collectors completed a $2 \mathrm{~h}$ review training to reacquaint them with the instruments and learn additional post-test data collection surveys.

\section{Data collection timing}

Children were interviewed at baseline and postintervention using the Camp NERF child assessment form, which consisted of nutrition, physical activity, mental health and psychosocial questionnaires. Demographic information was obtained from the Camp NERF caregiver assessment form completed with each child's primary caregiver ${ }^{(2,17)}$. Twenty-four-hour dietary recalls were also conducted with children. In addition, child height and weight were measured.

Interviews took approximately $30 \mathrm{~min}$ and were conducted in participants' homes, the school site or another community location. The assessment form was data collector-administered, with the data collector reading each question verbatim, including all possible responses, and recording the participant's response. If the participant provided an ambiguous response, the data collector asked questions to probe for a specific response. For younger children, caregivers were asked to assist in completing and verifying responses from the child interview when deemed necessary.

\section{Outcome measures}

Demographic information was coded as follows. Child age was ascertained by date of birth, which was utilized for BMI $Z$-score calculations. For race, participants were classified as either Black or non-Black $(0=$ Black, $1=$ non-Black). Participants were classified as Black if their caregiver reported their child as being African, African American, or both African or African American and another race or ethnicity. All others were classified as non-Black. For household income, a binomial variable (low-income $=0 ; \quad$ non-low-income $=1$ ) was created. Annual household income data were collected categorically: (i) < \$US 10000; (ii) \$US 10001-20000; (iii) \$US 20001-30000; (iv) \$US 30001-40000; (v) \$US $40001-$ 50000 ; (vi) \$US $50001-60000$; (vii) \$US 60 001-80 000; and (viii) > \$US 80000 . Participants were assigned an income level based on the midpoint of their reported income range. This annual household income level was compared with national poverty guidelines ${ }^{(18)}$ and, based on the number of individuals living in the household (another question on the caregiver assessment form), participants were classified as low-income or non-low-income.

Children's height and weight were assessed using the National Health and Nutrition Examination Survey proto$\mathrm{col}^{(19)}$. They were measured by a trained data collector using a Hopkins Road Rod Portable Stadiometer and BalanceForm High Accuracy Digital Scale. Height and weight measurements were taken twice, averaged, and BMI $Z$-score was calculated using the statistical software Stata zanthro package, with age included as days calculated as the date of survey administration minus date of birth $^{(20)}$.

Domel et al.'s validated preferences survey ${ }^{(21,22)}$ was utilized to assess potential changes in child liking of fruits, vegetables and snacks under the presumption that preferences precede behaviour change ${ }^{(23)}$. This twenty-eightitem fruit and vegetable questionnaire lists ten fruits and ten vegetables and enquires about liking each item ('not a lot' $=0$, 'a little' $=1$ or 'a lot' $=2)$. Total $(0-40)$, fruit subscale (0-20) and vegetable subscale (0-20) 'liked it' scores were calculated. Subsequently, eight snack preference scenarios were presented, e.g. 'For a snack, do you prefer chips or veggies and dip?' Less healthy options were assigned a value of 0 and healthier options were assigned a value of 1 , and a healthy snack preference score on a scale of $0-8$ was calculated. Internal consistency $\alpha$ coefficients ${ }^{(24)}$ for the liking vegetable and fruit combined scale, vegetable subscale, fruit subscale and snack preferences scale were $0 \cdot 75,0 \cdot 67,0.60$ and 0.74 at baseline and $0.77,0.68,0.61$ and 0.72 postintervention, respectively.

The research plan for child dietary data was to collect three (two weekdays and one weekend day) $24 \mathrm{~h}$ dietary recalls ${ }^{(25-27)}$. However, due to staffing constraints and difficulty contacting caregivers, only one weekday $24 \mathrm{~h}$ dietary recall was completed at baseline and postintervention. The data were collected in-person, utilizing the USDA's five-step multi-pass dietary recall $\operatorname{method}^{(28,29)}$. Data were entered using the Nutrition Data System for Research (NDSR), version 2015(30). Dietary outcomes included daily whole fruit servings (cup equivalents), fruit juice servings (cup equivalents), total fruit servings (cup equivalents), total vegetable servings (cup equivalents), total fruit and vegetable servings (cup equivalents), sugar-sweetened beverage servings (cup equivalents) and total energy intake (kilocalories).

The ten-item School Physical Activity and Nutrition (SPAN) questionnaire was used to assess child physical activity and media-related sedentary behaviours ${ }^{(31-34)}$. Sufficiency in physical activity behaviours was based on the Youth Risk Behavior Surveillance System ${ }^{(35)}$ criteria and recommendations of at least $20 \mathrm{~min}$ of vigorous physical activity on $3 \mathrm{~d} /$ week or at least $30 \mathrm{~min}$ of moderate physical activity on $5 \mathrm{~d} /$ week $^{(31-34)}$. Physical activity variables were created $(0=$ insufficient moderate or vigorous physical activity; $1=$ sufficient moderate or vigorous physical activity). Finally, an overall insufficient physical activity variable was created, defined as participating in less than $4 \mathrm{~d}$ of moderate physical activity for $30 \mathrm{~min}$ and less than $2 \mathrm{~d}$ of vigorous physical activity for $20 \mathrm{~min}$.

Child self-concept was assessed using the thirty-item Positive and Negative Affect Schedule (PANAS) survey ${ }^{(36,37)}$. 
Thirty feelings or emotions (fifteen-item positive and fifteen-item negative affect subscales) were presented to the respondent and they were asked how often or to what extent they experienced those feelings or emotions over the past couple of weeks on a 4-point Likert scale $(0=$ 'very slightly or not at all'; $4=$ 'extremely or a lot'). Positive and negative affect scale scores from 0 to 60 were calculated, which for the scale representing positive affect, a higher score representing more positive feelings and for the scale representing negative affect, a higher score representing more negative feelings. Internal consistency $\alpha$ coefficients $^{(24)}$ for positive and negative affect scales baseline and post-intervention were 0.75 and 0.88 and $0 \cdot 81$ and $0 \cdot 88$, respectively.

The Social Support for Healthy and Unhealthy Eating Questionnaire for Children consisted of four subscales to measure support from friends or peers and caregivers for healthy and unhealthy eating ${ }^{(38,39)}$. The support for healthy eating scales contained four items and the support for unhealthy eating scales contained three items. Each question inquired as to how often a friend or peer and caregiver performed a task related to healthy and unhealthy eating activities. Response options were on a 5-point Likert scale ( $0=$ 'never'; $4=$ 'very often'). Scale scores ranged from 0 to 16 for the healthy eating scales (a higher score represented higher support for healthy eating) and from 0 to 12 for the unhealthy eating scales (a higher score represented higher support for unhealthy eating). Internal consistency $\alpha$ coefficients $^{(24)}$ for peer support for healthy eating, peer support for unhealthy eating, caregiver support for healthy eating and caregiver support for unhealthy eating scales were $0.79,0.68,0.56$ and 0.45 baseline and $0.76,0.68$, 0.67 and 0.64 post-intervention, respectively.

\section{Process measures}

Daily child attendance data at the individual level were collected by the Camp NERF community partner starting in July (week 3 of the 8-week intervention), when attendance at SFSP sites normalizes, through the end of the intervention.

To assess satisfaction with Camp NERF programming, child participants completed a brief satisfaction survey during the post-intervention interview. Children were asked to rate how much they liked or enjoyed Camp NERF on a 4-point Likert scale ( $1=$ 'I didn't like it'; $4=$ 'I liked it a lot'). Also, children were asked three open-ended questions: (i) 'What did you like best about Camp NERF?'; (ii) 'What didn't you like about Camp NERF?'; and (iii) 'What would you change about Camp NERF?'

A Camp NERF daily process evaluation form was developed for the present study and completed by trained process evaluators who were not involved with intervention implementation. For each component of the Camp NERF curriculum - 4-H Programming (Active Control sites only) ${ }^{(40)}$, CATCH (Coordinated Approach to Child Health) Nutrition Education and Physical Education (Standard Care and Enhanced Care sites) $)^{(41-43)}$ and COPE (Creating
Opportunities for Personal Empowerment) Mental Health Education (Enhanced Care sites only) ${ }^{(44)}$ - number of minutes of each lesson and number of participants were recorded and seven 'yes' or 'no' questions pertaining to feasibility, fidelity and acceptability were answered. Space for additional comments for each question was also provided and answers were summarized.

\section{Data analysis}

Power was calculated using change in BMI $Z$-score as the primary outcome of interest. Based on results from a previous pilot test ${ }^{(45,46)}$, we assumed that between-subject variation was normally distributed with an SD of 1.03 and that between-site variation (nested within treatment group) was negligible. Under these assumptions, recruiting twenty participants per site (planning for $20 \%$ attrition) provided approximately $70 \%$ power to detect a difference of 0.5 points in change in BMI between the treatment group and either of the two control groups using a onesided test at $\alpha=0 \cdot 05$.

Exploratory data analyses were conducted. One child was considered an outlier (change BMI $Z$-score) and dropped from the baseline demographic and outcomes analyses, but was included in process measure analyses (i.e. retention). The $\chi^{2}$ test and ANOVA were completed to determine if there were any significant demographic differences by age, gender, race, income, baseline BMI $Z$-score and weight status category between intervention groups. Respective baseline and post-intervention means and proportions of all child outcomes were calculated.

Missing data were present due to sensitivity of questions for household income ( $n$ 12), fruit and vegetable preferences ( $n$ 2), snack preferences ( $n$ 3), self-concept positive affect ( $n$ 8), self-concept negative affect $(n 7)$, social support for healthy and unhealthy eating scales ( $n$ 3), physical activity ( $n$ 2), dietary intake ( $n 14)$, height $\left(n\right.$ 7) and weight $(n 7)$. Multiple imputation ${ }^{(47,48)}$ was employed to fill missing data values using the MI procedure in the statistical software package Stata IC version $14^{(20)}$. Imputation models were built with predicting variables including: site, site type, gender, age, race/ethnicity, total Camp NERF attendance, number of adults residing in the household and total number of individuals residing in the household, as well as dependent variables of interest when imputing an independent variable for analysis models. Fifty imputation iterations were run for each missing value and convergence was met ${ }^{(6)}$.

Cronbach's $\alpha$ tests of internal consistency were conducted for food preference, self-concept, and social support for healthy and unhealthy eating scale and subscale responses at baseline and post-intervention (reported above). The intervention was tested by comparing change from baseline to post-intervention in fruit and vegetable preferences, snack preference, dietary intake, positive affect, negative affect, friend or peer and caregiver social 
support for healthy and unhealthy eating (Hypothesis 3) and BMI Z-score (Hypothesis 2).

For fruit and vegetable preferences, snack preferences, dietary intake, positive and negative affect, and social support for healthy and unhealthy eating, mixed-effects hierarchical linear regression models were fit with site type as the primary predictor. Other covariates included baseline BMI $Z$-score, income, race and attendance. These models (Models 1-17; Hypothesis 3) were calculated using the following equation:

$$
\begin{aligned}
y_{i j t}= & \mu+\beta_{1}(\text { Site Type }) X_{1 i j t}+\beta_{2}(\text { Baseline } z B M I) X_{2 i j t} \\
& +\beta_{3}(\text { Income }) X_{3 i j t}+\beta_{4}(\text { Race }) X_{4 i j t}+\beta_{5}(\text { Attendance }) X_{5 i j t} \\
& +\delta_{j}+\epsilon_{i j t}
\end{aligned}
$$

where $y_{i j t}$ is the change in response/outcome variable for the $t$ th child $\left(t=1, \ldots, N_{i j}\right)$ in treatment $i$ (Enhanced Care $v$. Standard Care or Active Control) at site $j(j=1, \ldots, 9) . X_{1}$, $X_{2}, X_{3}, X_{4}$ and $X_{5}$ are the predictor variables site type, baseline BMI $Z$-score (zBMI), income, race and attendance, and $\beta_{1}, \beta_{2}, \beta_{3}, \beta_{4}$ and $\beta_{5}$ are the corresponding regression coefficients. $\mu$ is the $y$-intercept term; $\delta_{j}$ is a random effect for the site; and $\epsilon_{i j t}$ is a random measurement error term. In Models $1-17, y_{i j t}$ is $\Delta$ Vegetable Preference; $\Delta$ Fruit Preference; $\Delta$ Vegetable and Fruit Preference; $\Delta$ Snack Preference; $\Delta$ Total Energy Intake; $\Delta$ Whole Fruit Servings; $\Delta$ Fruit Juice Servings; $\Delta$ Total Fruit Servings; $\Delta$ Total Vegetable Servings; $\Delta$ Total Fruit and Vegetable Servings; $\Delta$ Sugar-Sweetened Beverage Servings; $\Delta$ Positive Affect; $\Delta$ Negative Affect; $\Delta$ Caregiver Support for Healthy Eating; $\Delta$ Peer Support for Healthy Eating; $\Delta$ Caregiver Support for Unhealthy Eating; $\Delta$ Peer Support for Unhealthy Eating.

Similarly, for BMI $Z$-score, a mixed-effects hierarchical linear regression model was fit with site type as the primary predictor. Covariates included income, race and attendance. This model (Model 18; Hypothesis 2) was calculated using the following equation:

$$
\begin{aligned}
y_{i j t}= & \mu+\beta_{1}(\text { Site Type }) X_{1 i j t}+\beta_{2}(\text { Income }) X_{2 i j t} \\
& +\beta_{3}(\text { Race }) X_{3 i j t}+\beta_{4}(\text { Attendance }) X_{4 i j t}+\delta_{j}+\epsilon_{i j t}
\end{aligned}
$$

where $y_{i j t}$ is $\Delta$ BMI $Z$-score.

For physical activity outcomes - sufficient moderate physical activity, sufficient vigorous physical activity and insufficient physical activity - mixed-effects hierarchical logistic regression models were fit with site type as the primary predictor. Other covariates included baseline moderate/vigorous physical activity or baseline insufficient physical activity, baseline BMI $Z$-score, income, race and attendance. These models (Models 19-21; Hypothesis 3) were calculated using the following equation:

$$
\begin{aligned}
y_{i j t}= & \mu+\beta_{1}(\text { Site Type }) X_{1 i j t}+\beta_{2}(\text { Baseline Physical Activity }) X_{2 i j t} \\
& +\beta_{3}(\text { Income }) X_{3 i j t}+\beta_{4}(\text { Race }) X_{4 i j t}+\beta_{5}(\text { Attendance }) X_{5 i j t} \\
& +\beta_{6}(\text { Baseline } z B M I) X_{6 i j t}+\delta_{j}+\epsilon_{i j t}
\end{aligned}
$$

where $y_{i j t}$ is Sufficient Moderate Physical Activity; Sufficient Vigorous Physical Activity; Insufficient Physical Activity.

Mixed-effects hierarchical linear and logistic regression models account for any random-effects variability at the site level. Introducing this random effect implies that there were two sources of variability in these models: (i) a between-site variability (captured in the $\sigma_{\delta}^{2}$ variance term) and (ii) a residual per-observation or within-site variability (captured in the $\sigma_{\epsilon}^{2}$ variance term). Furthermore, these models estimated the degree to which the response for participants at the same treatment site were correlated.

The study was approved by The Ohio State University Social and Behavioral Institutional Review Board (approval number 2014B0197).

\section{Results}

\section{Baseline demographics}

Eighty-seven children enrolled in Camp NERF. Descriptive summaries of sample baseline measures are presented in Table 1. There were significant differences between groups in income level $(P<0 \cdot 01)$ and baseline weight status (BMI $Z$-score $(P=0 \cdot 01)$ and weight classification $(P=0 \cdot 02))$. Standard Care participants were had higher income and higher mean BMI $Z$-score at baseline.

\section{Process outcomes}

\section{Feasibility}

Three of the twelve sites (two Active Control and one Standard Care) dropped out after study launch due to low attendance, which resulted in a $75 \%$ site retention rate (Table 2). Eighty-one children (93.10\% retention) completed post-intervention assessments (Table 2). Retention rates by site type were $95 \cdot 24 \%$ ( $n$ 20), 93.10\% ( $n$ 27) and 91.89\% ( $n$ 34) for Active Control, Standard Care and Enhanced Care sites, respectively. There was no significant difference in participant retention rate between sites $(P=0 \cdot 89$; Table 2$)$.

Daily attendance (month of July; total possible days $n$ 23) was examined in two ways: (i) raw attendance and (ii) attendance among children who participated in Camp NERF more than once. The latter measure may be more accurate, given that Camp NERF sites were open USDA SFSP feeding sites. When considering raw attendance, the mean was 56.77 ( $\mathrm{se} 3.66) \%$. Attendance rates by site type were 66.67 (SE 8.24) \%, 73.70 (SE 3.89) \% and 38.33 (SE 5.16) $\%$ for Active Control, Standard Care and Enhanced Care sites, respectively, and varied significantly (Table 2; $P<0.01)$. When considering attendance among children 
Table 1 Camp NERF baseline demographics, by site type, of school-aged children (kindergarten-5th grade) from low-income urban neighbourhoods, Columbus, OH, USA, June-August 2015

\begin{tabular}{|c|c|c|c|c|c|c|c|c|c|}
\hline & \multicolumn{2}{|c|}{$\begin{array}{l}\text { Total sample } \\
\quad(n \text { 86) }\end{array}$} & \multicolumn{2}{|c|}{$\begin{array}{l}\text { Active Control } \\
\quad(n \text { 21) }\end{array}$} & \multicolumn{2}{|c|}{$\begin{array}{c}\text { Standard Care } \\
(n 28)\end{array}$} & \multicolumn{2}{|c|}{$\begin{array}{l}\text { Enhanced Care } \\
\quad(n \text { 37) }\end{array}$} & \multirow[b]{2}{*}{$P$ value } \\
\hline & Mean or \% & SE or $n$ & Mean or $\%$ & SE or $n$ & Mean or $\%$ & SE or $n$ & Mean or $\%$ & SE or $n$ & \\
\hline $\begin{array}{l}\text { Age (years), mean and SE } \\
\text { Gender, } \% \text { and } n\end{array}$ & 7.56 & 0.20 & $7 \cdot 71$ & 0.45 & $7 \cdot 71$ & 0.27 & $7 \cdot 35$ & 0.33 & $0.67 \|$ \\
\hline Male & 43.02 & 37 & $38 \cdot 10$ & 8 & $42 \cdot 86$ & 12 & 45.95 & 17 & \\
\hline Female & 56.98 & 49 & 61.90 & 13 & $57 \cdot 14$ & 16 & 54.05 & 20 & \\
\hline Incomet, $\%$ and $n$ & & & & & & & & & $<0.01 \rrbracket$ \\
\hline Low-income & 59.46 & 44 & $77 \cdot 78$ & 14 & 24.00 & 6 & 77.42 & 24 & \\
\hline Non-low-income & 40.54 & 30 & $22 \cdot 22$ & 4 & 76.00 & 19 & $22 \cdot 58$ & 7 & \\
\hline Race $\ddagger, \S, \%$ and $n$ & & & & & & & & & $0.11 \rrbracket$ \\
\hline Black & 89.53 & 77 & 80.95 & 17 & $85 \cdot 71$ & 24 & $97 \cdot 30$ & 36 & \\
\hline Non-Black & 10.47 & 9 & 19.05 & 4 & 14.29 & 4 & $2 \cdot 70$ & 1 & \\
\hline BMI Z-score§, mean and SE & 0.58 & $0 \cdot 12$ & 0.05 & 0.19 & 0.95 & $0 \cdot 19$ & 0.61 & 0.21 & $0.01 \|$ \\
\hline BMI classification $\S, \%$ and $n$ & & & & & & & & & $0.02 \pi$ \\
\hline Normal & $70 \cdot 51$ & 55 & $95 \cdot 24$ & 20 & 51.85 & 14 & $70 \cdot 00$ & 21 & \\
\hline Overweight & 16.67 & 13 & 4.76 & 1 & $22 \cdot 22$ & 6 & $20 \cdot 00$ & 6 & \\
\hline Obese & $12 \cdot 82$ & 10 & 0.00 & 0 & $25 \cdot .92$ & 7 & $10 \cdot 00$ & 3 & \\
\hline
\end{tabular}

†For household income, a binomial variable (low-income $=0$; non-low-income $=1$ ) was created. Annual household income data were collected categorically: (i) < $\$$ US 10 000; (ii) $\$$ US 10 001-20 000; (iii) $\$$ US 2000130 000; (iv) \$US $30001-40000$; (v) \$US 40001-50000; (vi) \$US 50001-60 000; (vii) \$US 60001-80000; and (viii) > \$US 80000 . Based on responses to the categorical annual household income question, participants were assigned an income-level based on the midpoint between the income range. For example, if a participant responded that her/his annual household income was between $\$ U S 10001$ and $\$ U S 20000, \mathrm{~s} /$ he was assigned an income level of \$US 15000 . This annual household income level was compared with the national poverty guidelines ${ }^{(18)}$ and, based on the number of individuals living in the household (another question on the caregiver assessment form), participants were classified is low-income or non-low-income.

¥Participants were classified as Black if their caregiver reported the child as being African, or African American, or both African or African American and another race/ethnicity.

$\S$ Missing values pre-set; numbers presented do not represent imputed values.

By ANOVA.

IBy $x^{2}$ test. 
Table 2 Camp NERF daily feasibility and fidelity process evaluation outcomes in low-income urban neighbourhoods, Columbus, OH, USA, June-August 2015

\begin{tabular}{|c|c|c|c|c|c|c|c|c|}
\hline & \multicolumn{2}{|c|}{ Active Control } & \multirow{2}{*}{\multicolumn{2}{|c|}{$\begin{array}{c}\text { Standard Care } \\
\text { CATCH Nutrition } \\
\text { Education and } \\
\text { Physical Education }\end{array}$}} & \multicolumn{4}{|c|}{ Enhanced Care } \\
\hline & \multicolumn{2}{|c|}{ 4-H Programming } & & & $\begin{array}{r}\text { CATCH I } \\
\text { Educati } \\
\text { Physical E }\end{array}$ & $\begin{array}{l}\text { utrition } \\
\text { ר and } \\
\text { lucation }\end{array}$ & $\begin{aligned} \text { COPE } \\
\text { Health } \mathrm{E}\end{aligned}$ & $\begin{array}{l}\text { Mental } \\
\text { ducation }\end{array}$ \\
\hline & $\begin{array}{l}\% \text { or } \\
\text { Mean }\end{array}$ & $n$ or SE & $\begin{array}{l}\% \text { or } \\
\text { Mean }\end{array}$ & $n$ or SE & $\begin{array}{l}\% \text { or } \\
\text { Mean }\end{array}$ & $n$ or SE & $\begin{array}{l}\% \text { or } \\
\text { Mean }\end{array}$ & $n$ or SE \\
\hline Retention, $\%$ and $n$ & $95 \cdot 24$ & 20 & $93 \cdot 10$ & 27 & $91.89 \|$ & 34 & & \\
\hline Attendance $+(\%)$, mean and SE & 66.67 & 8.24 & 73.70 & 3.89 & $38 \cdot 33 \pi^{\star *}$ & $5 \cdot 16$ & & \\
\hline Attendance $\ddagger(\%)$, mean and SE & $77 \cdot 78$ & $6 \cdot 51$ & $76 \cdot 43$ & $2 \cdot 88$ & $50 \cdot 32 \rrbracket^{\star \star}$ & 5.00 & & \\
\hline No. of participants§, mean and SE & 9.65 & 1.28 & $2 \cdot 81$ & 0.30 & 6.50 & 0.37 & 10.09 & 0.62 \\
\hline No. of minutes of programming, mean and SE & 73.44 & $11 \cdot 20$ & 35.53 & 1.95 & 39.58 & 1.37 & $20 \cdot 88$ & $1 \cdot 19$ \\
\hline Was this the planned lesson for the day? \% Yes & $90 \cdot 48$ & - & 89.47 & - & 83.33 & - & 79.07 & - \\
\hline $\begin{array}{l}\text { Did camp counsellors present all material to meet } \\
\text { lesson objectives? \% Yes }\end{array}$ & $100 \cdot 00$ & - & 94.74 & - & 78.79 & - & 79.07 & - \\
\hline $\begin{array}{l}\text { Were participants actively engaged \& involved in } \\
\text { the programme? \% Yes }\end{array}$ & $76 \cdot 19$ & - & $84 \cdot 21$ & - & 89.39 & - & 85.05 & - \\
\hline $\begin{array}{l}\text { Did the camp counsellors create a positive, interactive } \\
\text { environment? \% Yes }\end{array}$ & $85 \cdot 71$ & - & $94 \cdot 74$ & - & $77 \cdot 27$ & - & $76 \cdot 74$ & - \\
\hline $\begin{array}{l}\text { Did camp counsellors help participants problem solve } \\
\text { regarding barriers to goal attainment? \% Yes }\end{array}$ & $100 \cdot 00$ & - & 94.74 & - & $75 \cdot 00$ & - & 83.72 & - \\
\hline Did camp counsellors allow time for questions? \% Yes & $95 \cdot 24$ & - & 94.74 & - & 53.79 & - & 76.74 & - \\
\hline Did camp counsellors answer questions adequately? \% Yes & $85 \cdot 71$ & - & 94.74 & - & 54.55 & - & $72 \cdot 09$ & - \\
\hline
\end{tabular}

CATCH, Coordinated Approach to Child Health; COPE, Creating Opportunities for Personal Empowerment.

${ }^{* *} P<0.01$.

†Attendance at site.

$\ddagger$ Attended $>1$ time.

$\S$ Attendance at programming delivered at site (note: children were not required to participate in programming at the site).

$\|$ By $X^{2}$ test.

IBY ANOVA.

who participated in Camp NERF more than once, the mean was 66.75 (se 3.08) \%. Attendance rates by site type were 77.78 (se 6.51) \%, 76.43 (se 2.88) \% and 50.32 (se 5.00) \% for Active Control, Standard Care and Enhanced Care sites, respectively, and varied significantly (Table $2 ; P<0 \cdot 01$ ).

Camp NERF child participants were highly satisfied with programming offered. The overall mean satisfaction score was 3.33 (SE 0.15), which falls between 'I liked it' and 'I liked it a lot' on the satisfaction survey. Mean scores by site type were 3.53 (se 0.21), 3.56 (se 0.24) and 3.04 (se 0.28) for Active Control, Standard Care and Enhanced Care site participants, respectively, and did not differ significantly between site type $(P=0 \cdot 26)$. Responses to open-ended questions on the satisfaction survey are summarized in Table 3.

\section{Fidelity}

Overall, high fidelity was demonstrated for all Camp NERF components, as was the 4- $\mathrm{H}$ curriculum at the Active Control sites (Table 2). Delivery of the intended lesson occurred between 79 and $90 \%$ of the time. The entirety of material was presented $79-100 \%$ of the time. Child participants were actively engaged $76-89 \%$ of the time. Camp NERF counsellors were able to create positive and interactive environments $77-95 \%$ of the time and help child participants overcome barriers and problem solve $75-100 \%$ of the time.

The mean number of children participating in Active Control (4-H) and Standard Care (CATCH) programming was $9 \cdot 65$ (SE 1.28) and 2.81 (SE 0.30), respectively. The mean number of children participating in Enhanced Care programming was $6 \cdot 50$ (SE 0.37; CATCH portion) and 10.09 (SE 0.62 ; COPE portion). Additionally, the mean length of programming was 73.44 (sE 11.20) min for Active Control (4-H) and 35.53 (sE 1.95) min for Standard Care (CATCH). For Enhanced Care, the mean length of programming was 39.58 (SE 1.37) $\min (\mathrm{CATCH})$ and 20.88 (sE 1.19) $\min$ (COPE). These times are consistent with expected delivery times ${ }^{(2)}$.

\section{Child outcomes}

\section{Anthropometrics}

There was no intervention effect on weight status (Table 4). Overall mean change in BMI $Z$-score from baseline to post-intervention was -0.03 (sE 0.05; CI -0.13, $0 \cdot 06$ ). Mean change in BMI $Z$-score was $-0 \cdot 13$ (SE 0.10; CI $-0 \cdot 33,0.06)$ for males and 0.04 (se 0.04; CI -0.05, 0.12) for females.

\section{Child nutrition, physical activity, mental bealth and} psychosocial outcomes

There was no intervention effect on vegetable, fruit, vegetable and fruit, or snack preference outcomes (Table 4). In addition, there was no intervention effect on dietary outcomes. Regarding physical activity outcomes, there was no intervention effect; however, overall proportions of participants achieving sufficient moderate (5.24\%) and sufficient vigorous (4.36\%) physical activity improved from baseline to post-intervention. In addition, there was an overall decrease (12.99\%) in the proportion 
Table 3 Summary of Camp NERF participant satisfaction survey responses from school-aged children (kindergarten-5th grade) from lowincome urban neighbourhoods, Columbus, OH, USA, June-August 2015

\begin{tabular}{|c|c|c|c|}
\hline \multirow[b]{2}{*}{ Question } & \multicolumn{2}{|c|}{ Response } & \multirow[b]{2}{*}{$P$ value } \\
\hline & Mean & $\mathrm{SE}$ & \\
\hline Satisfaction (scale: $1-4$ ), mean and SE & & & 0.26 \\
\hline Overall $(n 77)$ & 3.33 & 0.15 & \\
\hline Active Control $(n 20)$ & 3.53 & 0.21 & \\
\hline Standard Care $(n 25)$ & 3.56 & 0.24 & \\
\hline Enhanced Care ( $n$ 32) & 3.04 & 0.28 & \\
\hline $\begin{array}{l}\text { What did you like best } \\
\text { about Camp NERF? }\end{array}$ & \multirow{3}{*}{\multicolumn{3}{|c|}{$\begin{array}{l}\text { - Interacting with the Camp NERF counsellors } \\
\text { - Taste tests } \\
\text { - CATCH physical education games } \\
\text { - Going to the gym, outside, the playground, etc. } \\
\text { - Making friends } \\
\text { - Lessons that included songs } \\
\text { - Learning } \\
\text { - Making crafts (Active Control sites Cloverbuds curriculum) } \\
\text { - Lack of variety in games } \\
\text { - Length; desired for Camp NERF to be longer } \\
\text { - Sitting down during lessons } \\
\text { - Certain activities, e.g. kickball, matball } \\
\text { - Lack of ability for input to modify curriculum, i.e. suggesting games } \\
\text { - Lack of running around, going outside and exercising (Active Control sites) } \\
\text { - Lengthening the time for the COPE curriculum } \\
\text { - Inclusion of specific activities, i.e. soccer, scavenger hunts, piñatas, crafts, etc. } \\
\text { - Older kids desiring to read to the younger kids } \\
\text { - Request for more physical activity opportunities at Active Control sites, e.g. going } \\
\text { to the park, going to the gym }\end{array}$}} \\
\hline $\begin{array}{l}\text { What didn't you like about } \\
\text { Camp NERF? }\end{array}$ & & & \\
\hline $\begin{array}{l}\text { What would you like changed } \\
\text { about Camp NERF? }\end{array}$ & & & \\
\hline
\end{tabular}

COPE, Creating Opportunities for Personal Empowerment.

of participants who engaged in insufficient physical activity from baseline to post-intervention. Finally, there was no intervention effect on self-concept or perceived social support from caregivers or peers for healthy and unhealthy eating (Table 4).

\section{Discussion}

The summertime presents a window of risk for unhealthy weight gain among low-income, minority children ${ }^{(6-12)}$. Few research efforts have been directed at testing evidence-informed nutrition and physical activity programmes to equip children with necessary knowledge, skills and other resources to prevent excess weight gain during the summer. Camp NERF is the first evidenceinformed intervention to address disproportionate childhood weight gain in underserved children during the summer.

In the current study, we observed feasibility and fidelity of Camp NERF, but no intervention effect. Rather a prevention of unhealthy weight gain was observed across all groups, indicating that participation in structured programming of any type (health behaviour-related or not) may prevent unhealthy weight gain during the summer. This finding is consistent with the physical activity data in which there were overall proportional improvements with regard to physical activity from baseline to post-intervention. However, it is worth noting that due to reliance on the Youth Risk Behavior Surveillance System physical activity recommendations ( $20 \mathrm{~min}$ of vigorous physical activity on $3 \mathrm{~d} /$ week or $30 \mathrm{~min}$ of moderate physical activity on $5 \mathrm{~d}$ /week), children in the present study designated as sufficiently active may in fact not be meeting the Centers for Disease Control and Prevention's recommendation of $60 \mathrm{~min}$ or more every day of the week ${ }^{(49)}$.

Results from the current study are in line with the Structured Days Hypothesis, which posits that obesogenic behaviours are better regulated when a child is exposed to structure (e.g. a school day, compared with times they are not exposed to structure, e.g. weekend days or summer ${ }^{(14)}$. Specifically, these results suggest that when a child participates in structured programming of any type (i.e. health behaviour-related or not) during the summer (e.g. a summer camp, where they have access to nutritious foods and opportunities for safe play), obesogenic behaviours may be better regulated, contributing to a maintenance, as opposed to a decline, in health. That said, the current study was not adequately powered to detect differences between groups. To avoid a premature acceptance of the null hypothesis, it is imperative for future efforts to be invested in repeating the study with a sufficient sample size. Also, it is important to reference the feasibility data, which indicated greater length (minutes) of lessons, higher fidelity of lesson implementation and greater satisfaction among participants at the Active 
Table 4 Impact of Camp NERF intervention on outcomes of school-aged children (kindergarten-5th grade) from low-income urban neighbourhoods, Columbus, OH, USA, June-August 2015

\begin{tabular}{|c|c|c|c|c|c|c|c|c|c|c|}
\hline & B0 (Mean) & SE & T1 (Mean) & SE & $\Delta$ Mean & SE & $\beta$ & SE & $P$ value & $95 \% \mathrm{Cl}$ \\
\hline \multicolumn{11}{|c|}{$\begin{array}{l}\text { Food preferences } \\
\text { Liked vegetable (0-20) }\end{array}$} \\
\hline & 13.24 & 0.88 & 13.55 & 1.05 & & 0.73 & 0.72 & 0.91 & 0.43 & $-1.07,2.41$ \\
\hline Standard Care & 12.07 & 0.75 & 10.50 & 0.77 & -1.50 & 0.20 & 0.13 & 0.97 & 0.89 & $-1.77,2.03$ \\
\hline \multirow{2}{*}{\multicolumn{11}{|c|}{ Liked fruit $(0-20)$}} \\
\hline & & & & & & & & & & \\
\hline Active Control & 16.85 & 0.62 & $17 \cdot 30$ & 0.52 & 0.55 & 0.41 & 1.10 & 0.96 & 0.25 & $-0.78,2.99$ \\
\hline Standard Care & $16 \cdot 21$ & 0.55 & 14.65 & 0.65 & $-1.57^{\star \star}$ & 0.41 & -1.26 & 1.03 & 0.22 & $-3.28,0.75$ \\
\hline \multirow{2}{*}{\multicolumn{11}{|c|}{ Liked vegetable \& fruit (0-40) }} \\
\hline & & & & & & & & & & \\
\hline $\begin{array}{l}\text { Active Control } \\
\text { Standard Care }\end{array}$ & $\begin{array}{l}30.09 \\
28.28\end{array}$ & $\begin{array}{l}1.19 \\
1.13\end{array}$ & $\begin{array}{l}30.85 \\
25.15\end{array}$ & $\begin{array}{l}1.31 \\
1.33\end{array}$ & $\begin{aligned} & 1.00 \\
&-3.08^{\star \star}\end{aligned}$ & $\begin{array}{l}0.85 \\
0.77\end{array}$ & $\begin{array}{r}1.77 \\
-0.77\end{array}$ & $\begin{array}{l}1.51 \\
1.60\end{array}$ & $\begin{array}{l}0.24 \\
0.63\end{array}$ & $\begin{array}{l}-1 \cdot 18,4.73 \\
-3.90,2 \cdot 36\end{array}$ \\
\hline Enhanced Care & $\begin{array}{l}28.28 \\
28.89\end{array}$ & 1.13 & 28.09 & 1.07 & $\begin{array}{l}-0.08 \\
-0.88\end{array}$ & 1.16 & $-0.7 /$ & $-\infty$ & 0.63 & $-0.00,-00$ \\
\hline \multicolumn{11}{|c|}{ Snack preference $(0-8)$} \\
\hline Active Control & 4.14 & 0.47 & 4.45 & 0.48 & 0.45 & 0.43 & 0.30 & 0.55 & 0.60 & $-0.79,1.38$ \\
\hline Standard Care & 4.39 & 0.38 & 5.12 & 0.39 & $0.77^{\star}$ & 0.30 & 0.99 & 0.56 & 0.08 & $-0.11,2.08$ \\
\hline Enhanced Care & $5 \cdot 13$ & 0.38 & 5.88 & 0.32 & $0.67^{\star}$ & 0.32 & - & - & - & - \\
\hline \multirow{2}{*}{\multicolumn{11}{|c|}{$\begin{array}{l}\text { Dietary intake } \\
\text { Total energyt (kcal/d) }\end{array}$}} \\
\hline & & & \multicolumn{5}{|c|}{$\begin{array}{l}\text { Total energyt (kcal/d) } \\
\text { Active Control }\end{array}$} & & & \\
\hline $\begin{array}{l}\text { Active Control } \\
\text { Standard Care }\end{array}$ & $\begin{array}{l}1693.15 \\
1964.32\end{array}$ & $\begin{array}{l}180.90 \\
148.73\end{array}$ & 1783.72 & $\begin{array}{l}100.90 \\
146.94\end{array}$ & -170.54 & 151.64 & 133.59 & $\begin{array}{l}338.69 \\
338\end{array}$ & 0.69 & $-530.58,797.76$ \\
\hline Enhanced Care & 1749.05 & 134.49 & 1567.98 & 141.16 & -161.51 & $218 \cdot 15$ & - & & - & - \\
\hline \multicolumn{11}{|c|}{ Total vegetable (servings/d) } \\
\hline Active Control & 1.60 & 0.46 & 1.54 & 0.29 & 0.04 & 0.57 & 0.56 & 0.99 & 0.57 & $-1 \cdot 38,2 \cdot 50$ \\
\hline Standard Care & 1.38 & 0.28 & 1.87 & 0.30 & 0.48 & 0.38 & 0.83 & 0.98 & 0.40 & $-1.09,2.76$ \\
\hline Enhanced Care & 2.41 & 0.37 & 1.66 & 0.38 & -0.60 & 0.66 & - & - & - & - \\
\hline \multicolumn{11}{|c|}{ Whole fruit (servings/d) } \\
\hline Active Control & 0.81 & 0.27 & 0.65 & 0.15 & -0.14 & 0.29 & 0.63 & 0.49 & 0.20 & $-0.34,1 \cdot 60$ \\
\hline Standard Care & 0.94 & 0.27 & 0.97 & 0.30 & 0.39 & 0.36 & 0.70 & 0.53 & 0.18 & $-0.33,1.73$ \\
\hline \multirow{2}{*}{\multicolumn{11}{|c|}{ Fruit juice (servings/d) }} \\
\hline & & & & & & & & & & \\
\hline $\begin{array}{l}\text { Active Control } \\
\text { Standard Care }\end{array}$ & $\begin{array}{l}1.42 \\
1.85\end{array}$ & $\begin{array}{l}0.28 \\
0.42\end{array}$ & $\begin{array}{l}1.51 \\
1.25\end{array}$ & $\begin{array}{l}0.36 \\
0.26\end{array}$ & $\begin{array}{r}0.10 \\
-0.82\end{array}$ & $\begin{array}{l}0.41 \\
0.45\end{array}$ & $\begin{aligned} 0.10 \\
-0.47\end{aligned}$ & $\begin{array}{l}0.70 \\
0.72\end{array}$ & 0.51 & $\begin{array}{l}-1.27,1.46 \\
-1.88,0.94\end{array}$ \\
\hline \multirow{2}{*}{\multicolumn{11}{|c|}{$\begin{array}{l}\text { Total fruit (servings/d) } \\
\text { Treare }\end{array}$}} \\
\hline & & & & & & & & & & \\
\hline Active Control & $2 \cdot 24$ & 0.39 & $2 \cdot 16$ & 0.46 & -0.04 & 0.42 & 0.30 & 0.86 & 0.43 & $-0.98,2 \cdot 30$ \\
\hline Standard Care & 2.80 & 0.47 & 2.23 & 0.39 & -0.42 & 0.53 & 0.66 & 0.83 & 0.73 & $-1.38,1.97$ \\
\hline \multirow{2}{*}{\multicolumn{11}{|c|}{ Total vegetable and fruit (servings/d) }} \\
\hline & & & & & & & & & & \\
\hline $\begin{array}{l}\text { Active Control } \\
\text { Standard Care }\end{array}$ & 3.84 & 0.66 & 3.71 & 0.50 & 0.00 & 0.65 & $1 \cdot 23$ & 1.36 & 0.37 & $-1.44,3.91$ \\
\hline $\begin{array}{l}\text { Standard Care } \\
\text { Enhanced Care }\end{array}$ & 4.18 & 0.52 & $\begin{array}{l}4.10 \\
3.12\end{array}$ & 0.52 & $\begin{array}{r}0.05 \\
-1.34\end{array}$ & 0.72 & $1 \cdot 17$ & 1.38 & 0.40 & $-1.53,3.88$ \\
\hline \multicolumn{11}{|c|}{$\begin{array}{l}\text { Enhanced Care } \\
\text { Sugar-sweetened beverage (servings/d) }\end{array}$} \\
\hline $\begin{array}{l}\text { Sugar-sweetened } \\
\text { Active Control }\end{array}$ & 0.44 & 0.19 & $1 \cdot 10$ & 0.33 & 0.63 & 0.37 & 0.19 & 0.60 & 0.76 & $-0.99,1.36$ \\
\hline Standard Care & 0.99 & 0.24 & 1.09 & 0.29 & -0.01 & 0.39 & -0.51 & 0.61 & 0.41 & $-1.71,0.69$ \\
\hline Enhanced Care & 0.49 & 0.15 & 0.83 & 0.22 & 0.31 & 0.32 & - & - & - & - \\
\hline
\end{tabular}




\begin{tabular}{|c|c|c|c|c|c|c|c|c|c|c|}
\hline & B0 (\%) & $n$ & T1 (\%) & $n$ & \multicolumn{2}{|c|}{$\Delta \%$} & $\beta$ & $\mathrm{SE}$ & $P$ value & $95 \% \mathrm{Cl}$ \\
\hline \multicolumn{11}{|l|}{ Physical activity } \\
\hline Active Control & 47.62 & 10 & 60.00 & 12 & \multirow{2}{*}{\multicolumn{2}{|c|}{$\begin{array}{c}12.38 \\
-4.67\end{array}$}} & 0.26 & 0.91 & 0.78 & $-1.52,2.03$ \\
\hline Standard Care & 39.29 & 11 & 34.62 & 9 & & & -0.76 & 0.89 & 0.40 & $-2.51,1.00$ \\
\hline \multirow{2}{*}{\multicolumn{11}{|c|}{ Sufficient moderate physical activity }} \\
\hline & & & & & & & & & & \\
\hline Active Control & 71.43 & 15 & 85.00 & 17 & & 0.39 & 0.93 & 0.67 & $-1 \cdot 43,2 \cdot 21$ \\
\hline Standard Care & 78.57 & 22 & $69 \cdot 23$ & 18 & \multirow{2}{*}{\multicolumn{2}{|c|}{$\begin{array}{r}-9.34 \\
9.60\end{array}$}} & -1.22 & 0.90 & 0.18 & $-2.99,0.55$ \\
\hline Enhanced Care & $72 \cdot 22$ & 26 & 81.82 & 27 & & & - & - & - & - \\
\hline \multicolumn{11}{|c|}{ Insufficient physical activity } \\
\hline Active Control & 47.62 & 10 & 30.00 & 6 & \multirow{2}{*}{\multicolumn{2}{|c|}{$\begin{array}{r}-17.62 \\
11.26\end{array}$}} & -0.04 & 0.74 & 0.85 & $-1.59,1.31$ \\
\hline Standard Care & 46.43 & 13 & 57.69 & 15 & & & 0.70 & 0.73 & 0.33 & $-0.72,2.13$ \\
\hline \multirow[t]{2}{*}{ Enhanced Care } & $65 \cdot 71$ & 23 & $36 \cdot 36$ & 12 & \multicolumn{2}{|c|}{$-29 \cdot 30^{*}$} & - & - & - & - \\
\hline & B0 (Mean) & $\mathrm{SE}$ & T1 (Mean) & SE & $\Delta$ (Mean) & $\mathrm{SE}$ & $\beta$ & SE & $P$ value & $95 \% \mathrm{Cl}$ \\
\hline \multicolumn{11}{|l|}{ Self-concept } \\
\hline \multicolumn{11}{|l|}{ Positive affect (0-60) } \\
\hline Active Control & $44 \cdot 20$ & 2.41 & $40 \cdot 65$ & 1.99 & $-3 \cdot 26$ & $2 \cdot 22$ & -3.99 & 3.91 & 0.31 & $-11.66,3.69$ \\
\hline Standard Care & 43.71 & 1.81 & 41.31 & $2 \cdot 30$ & -2.46 & 2.83 & -3.77 & 4.06 & 0.35 & $-11.72,4.18$ \\
\hline Enhanced Care & 41.58 & 1.45 & $40 \cdot 19$ & 1.88 & -0.21 & $2 \cdot 25$ & - & - & - & - \\
\hline \multicolumn{11}{|c|}{ Negative affect $(0-60)$} \\
\hline Active Control & 17.47 & 3.00 & $18 \cdot 22$ & 3.09 & 0.00 & 3.01 & $2 \cdot 27$ & 4.01 & 0.57 & $-5 \cdot 60,10 \cdot 14$ \\
\hline Standard Care & 22.79 & 2.82 & 22.08 & 2.60 & -1.32 & 2.38 & -1.85 & 4.04 & 0.65 & $-9.78,6.07$ \\
\hline Enhanced Care & 24.63 & 1.99 & 21.36 & 2.38 & $-2 \cdot 00$ & $2 \cdot 34$ & - & - & - & - \\
\hline \multicolumn{11}{|c|}{ Social support } \\
\hline \multicolumn{11}{|c|}{ Caregiver support for healthy eating $(0-16)$} \\
\hline Active Control & $10 \cdot 38$ & 0.58 & 9.50 & 0.79 & -0.85 & 0.75 & -0.64 & 1.42 & 0.65 & $-3.43,2 \cdot 15$ \\
\hline Standard Care & $10 \cdot 30$ & 0.69 & 9.76 & 0.84 & -0.52 & 0.78 & -1.37 & 1.49 & 0.36 & $-4.28,1.55$ \\
\hline Enhanced Care & 9.47 & 0.74 & $10 \cdot 39$ & 0.75 & 1.13 & 0.99 & - & - & - & - \\
\hline \multicolumn{11}{|c|}{ Peer support for healthy eating $(0-16)$} \\
\hline Active Control & $6 \cdot 10$ & $1 \cdot 11$ & $6 \cdot 60$ & 1.12 & 0.50 & $1 \cdot 15$ & 1.42 & 1.48 & 0.34 & $-1.48,4.32$ \\
\hline Standard Care & 6.03 & 0.74 & 4.40 & 0.80 & $-1.88^{*}$ & 0.72 & -1.23 & 1.50 & 0.41 & $-4 \cdot 16,1 \cdot 70$ \\
\hline Enhanced Care & 6.62 & 0.90 & 5.55 & 0.77 & -0.93 & 0.85 & - & - & - & - \\
\hline \multicolumn{11}{|c|}{$\begin{array}{l}\text { Enhanced Care } \\
\text { Caregiver support for unhealthy eating }(0-12)\end{array}$} \\
\hline Active Control & 4.19 & 0.53 & 3.60 & 0.60 & -0.70 & 0.55 & 0.38 & 1.05 & 0.72 & $-1.67,2.43$ \\
\hline Standard Care & 3.81 & 0.47 & 4.80 & 0.61 & 1.04 & 0.71 & 0.90 & 1.07 & 0.40 & $-1 \cdot 19,3.00$ \\
\hline Enhanced Care & 4.50 & 0.52 & 4.84 & 0.60 & 0.20 & 0.69 & - & - & - & - \\
\hline \multicolumn{11}{|c|}{ Peer support for unhealthy eating $(0-12)$} \\
\hline Active Control & 4.00 & 0.73 & $4 \cdot 10$ & 0.75 & 0.00 & 0.76 & 0.03 & 1.27 & 0.90 & $-2 \cdot 45,2 \cdot 51$ \\
\hline Standard Care & 5.63 & 0.66 & 5.00 & 0.76 & -0.68 & 0.95 & -1.55 & 1.28 & 0.23 & $-4.06,0.97$ \\
\hline Enhanced Care & 3.74 & 0.54 & 4.76 & 0.58 & 1.10 & 0.69 & - & - & - & - \\
\hline \multicolumn{11}{|c|}{ Anthropometrics } \\
\hline BMI Z-score $(-\infty$ & & & & & & & & & & \\
\hline Active Control & 0.05 & 0.19 & -0.12 & 0.22 & -0.11 & 0.07 & -0.10 & 0.15 & 0.48 & $-0.39,0.18$ \\
\hline Standard Care & 0.96 & 0.19 & 0.87 & 0.20 & -0.05 & 0.12 & -0.06 & 0.15 & 0.67 & $-0.35,0.22$ \\
\hline Enhanced Care & 0.61 & 0.21 & 0.71 & 0.21 & 0.03 & 0.05 & - & - & - & - \\
\hline
\end{tabular}

B0, baseline; T1, post-intervention.

Reference group = Enhanced Care

Predictor variables: site type (multinomial variable; $0=$ Enhanced Care, $1=$ Standard Care, $2=$ Active Control); income (dichotomous variable; $0=$ low-income, $1=$ non-low-income); race/ethnicity (dichotomous variable; $0=$ Black, $1=$ non-Black); baseline sufficient moderate physical activity (dichotomous variable; $0=$ not sufficient, $1=$ sufficient); baseline sufficient vigorous physical activity (dichotomous variable; $0=$ not sufficient, $1=$ sufficient); baseline insufficient physical activity (dichotomous variable; $0=$ sufficient, $1=$ insufficient); baseline BMI Z-score (continuous variable; $-\infty$ to $+\infty$ )

tTo 
Control and Standard Care sites compared with the Enhanced Care sites. In the future, more work needs to be done to integrate the CATCH and COPE curricula into daily site activities to assure dose equality, and COPE may need additional adaptations to assure age-appropriateness and suitability for delivery in the summer camp setting.

Males' overall change in BMI $Z$-score was negative compared with females' overall change in BMI $Z$-score, which was positive. These data are consistent with national trends, which indicate that girls are at increased risk for overweight and obesity and for inappropriate weight gain during the summer ${ }^{(1,11,12)}$ and that as children age, girls tend to be less physically active and more sedentary than boys ${ }^{(50,51)}$. Mere exposure to a more structured day may not have the same beneficial effects on weight status for girls and must be explored in future research.

The current study had many strengths. To our knowledge, Camp NERF is one of the first evidence-informed interventions designed specifically to address the issue of unhealthy summer weight gain among economically disadvantaged school-aged children. The study design was a group randomized controlled trial, strengthening the interpretability and generalizability of the results. Finally, the evaluation plan was robust in that it included an assessment of feasibility and fidelity outcomes, as well as measures of health behaviours and anthropometrics.

There were also limitations. First, the target sample size of twenty participants per site was not achieved. Given the small sample size, along with an imbalance in sample size across groups with respect to income, a key confounding variable, the results presented here should be interpreted with caution and the experiment should be replicated to avoid premature acceptance of the null hypothesis ${ }^{(52)}$. At most sites, child attendance was consistently more than twenty individuals; however, ability to obtain caregiver permission and consent was difficult as it is not required for caregivers to drop off or pick up their children from open SFSP sites. Investigators of future studies utilizing open USDA SFSP sites as locations of research should explore passive caregiver permission and consent options with their respective Institutional Review Board. A second limitation was the lack of a true control group. Because Camp NERF was coupled with the USDA SFSP, a federal child nutrition programme, the statutory right for participation applies. Ethically, restricting participation in open SFSP sites was not allowable. Future research should focus on identifying ways (i.e. alternative recruitment methods) to include a control group (i.e. children who do not attend SFSP sites) that are ethically compliant. For instance, recruiting and enrolling participants (i.e. both those who do and do not intend to attend an SFSP site during the summer) prior to the end of the school year and tracking them longitudinally into the following school year. A final limitation is the limited or lack of validity testing of certain subjective measures among younger children, which reemphasizes the need to exercise caution in interpreting findings from the current study and demonstrates the need for future research in this area of inquiry.

\section{Conclusions}

Camp NERF built on successful childhood obesity prevention interventions that include nutrition and physical activity components, concurrent knowledge and skill building, coupling of intervention curriculum to availability of healthy foods, and opportunity for physical activity and play ${ }^{(53,54)}$. Studying the impact of such an intervention over the summer provided valuable information to address a high-risk period for children who are vulnerable to excessive summer weight gain. Results from the current study indicate that mere engagement in programming ( $v$. programming type, health behaviour-related or not) may lead to prevention of weight gain, which has direct implications for child nutrition policy with regard to the SFSP. However, to conclusively determine the lack of an intervention effect, it will be important for future research to be adequately powered. In addition, as there is a near complete dearth of information regarding health behaviours and environmental settings of disadvantaged school-aged children during the summer, future studies should include an in-depth examination of key dietary and physical activity behaviours as well as food, physical activity and social environments of children.

\section{Acknowledgements}

Acknowledgements: The authors thank the Camp NERF participants and their community partners, City of Columbus, Columbus Recreation and Parks Department, and Columbus City Schools. Financial support: Aetna Foundation and The Ohio State University Office of Outreach and Engagement provided for funding this study. The funders had no role in the design, analysis or writing of this article. Conflict of interest: B.M. is the founder and creator of COPE2thrive, LLC. All other authors declared no conflict of interest. Authorship: C.G. conceptualized and designed the study. L.C.H. coordinated and supervised data collection and carried out the analyses. L.C.H. drafted the initial manuscript and reviewed and revised the paper with C.G. C.H. provided direction on the statistical analyses. C.H., B.M., M.F., J.D.G., J.A.K. and I.E. provided input on the study design and methods; and reviewed and revised the manuscript. All authors approved the final manuscript as submitted and agree to be accountable for all aspects of the work. Ethics of human subject participation: This study was conducted according to the guidelines laid down in the Declaration of Helsinki and all procedures involving human subjects were approved by The Ohio State University Institutional Review Board. Written informed consent was obtained from all subjects. 


\section{References}

1. Ogden CL, Carroll MD, Kit BK et al. (2014) Prevalence of childhood and adult obesity in the United States, 2011-2012. JAMA 311, 806-814.

2. Hopkins LC, Fristad M, Goodway JD et al. (2016) Camp NERF: methods of a theory-based nutrition education recreation and fitness program aimed at preventing unhealthy weight gain in underserved elementary children during summer months. BMC Public Health 16, 1122.

3. Hales CM, Carroll MD, Fryar CD et al. (2017) Prevalence of Obesity Among Adults and Youth: United States, 20152016. NCHS Data Brief no. 288. Atlanta, GA: US Department of Health and Human Services, Centers for Disease Control and Prevention, National Center for Health Statistics.

4. Halfon N, Larson K \& Slusser W (2013) Associations between obesity and comorbid mental health, developmental, and physical health conditions in a nationally representative sample of US children aged 10 to 17. Acad Pediatr 13, 6-13.

5. Taras H \& Potts-Datema W (2005) Obesity and student performance at school. J Sch Health 75, 291-295.

6. von Hippel PT, Powell B, Downey DB et al. (2007) The effect of school on overweight in childhood: gain in body mass index during the school year and during summer vacation. Am J Public Health 97, 696-702.

7. Moreno JP, Johnston CA \& Woehler D (2013) Changes in weight over the school year and summer vacation: results of a 5-year longitudinal study. J Sch Health 83, 473-477.

8. Moreno JP, Johnston CA, Chen T-A et al. (2015) Seasonal variability in weight change during elementary school. Obesity (Silver Spring) 23, 422-428.

9. Kobayashi M \& Kobayashi M (2006) The relationship between obesity and seasonal variation in body weight among elementary school children in Tokyo. Econ Hum Biol 4, 253-261.

10. Smith DT, Bartee RT, Dorozynski CM et al. (2009) Prevalence of overweight and influence of out-of-school seasonal periods on body mass index among American Indian schoolchildren. Prev Chronic Dis 6, A20.

11. Baranowski T, O'Connor T, Johnston C et al. (2014) School year versus summer differences in child weight gain: a narrative review. Child Obes 10, 18-24.

12. Franckle R, Adler R \& Davison K (2014) Accelerated weight gain among children during summer versus school year and related racial/ethnic disparities: a systematic review. Prev Chronic Dis 11, E101.

13. Briefel RR, Crepinsek MK, Cabili C et al. (2009) School food environments and practices affect dietary behaviors of US public school children. J Am Diet Assoc 109, 2 Suppl., S91-S107.

14. Brazendale K, Beets MW, Weaver RG et al. (2017) Understanding differences between summer vs. school obesogenic behaviors of children: the structured days hypothesis. Int J Behav Nutr Phys Act 14, 100.

15. US Department of Agriculture, Food and Nutrition Service (2015) Summer Food Service Program. https://www.fns.usda. gov/sfsp/summer-food-service-program (accessed December 2015).

16. Hayes C, Rosso R, Anderson S et al. (2017) Hunger Doesn't Take a Vacation: Summer Nutrition Status Report. http:// www.frac.org/wp-content/uploads/2017-summer-nutritionreport-1.pdf (accessed November 2018)

17. Hopkins LC, Webster A, Sharn A et al. (2016) Camp NERF: caregiver outcomes from a theory-based nutrition education recreation and fitness program aimed at preventing unhealthy weight gain in disadvantaged children during summer months. Presented at The Obio State University Extension Family and Consumer Sciences All Programs Conference, Columbus, OH, USA, October 2016.
18. US Department of Health and Human Services (2015) 2015 Poverty Guidelines. https://aspe.hhs.gov/2015-povertyguidelines (accessed November 2018).

19. Centers for Disease Control and Prevention (2007) National Health and Nutrition Examinatory Survey (NHANES): Anthropometry Procedures Manual. Atlanta, GA: CDC.

20. StataCorp (2015) Stata Statistical Software: Release 14. College Station, TX: StataCorp LP.

21. Domel SB, Baranowski T, Davis H et al. (1993) Measuring fruit and vegetable preferences among 4th- and 5th-graders. Prev Med 22, 866-879.

22. Domel SB, Baranowski T, Davis HC et al. (1996) A measure of stages of change in fruit and vegetable consumption among fourth- and fifth-grade school children: reliability and validity. J Am Coll Nutr 15, 56-64.

23. Bandura A (2004) Health promotion by social cognitive means. Health Educ Behav 31, 143-164.

24. Tavakol M \& Dennick R (2011) Making sense of Cronbach's alpha. Int J Med Educ 2, 53-55.

25. Burrows TL, Martin RJ \& Collins CE (2010) A systematic review of the validity of dietary assessment methods in children when compared with the method of doubly labeled water. J Am Diet Assoc 110, 1501-1510.

26. Baxter Domel S, Thompson WO, Litaker MS et al. (2003) Accuracy of fourth-graders' dietary recalls of school breakfast and school lunch validated with observations: in-person versus telephone interviews. J Nutr Educ Behav 35, 124-134.

27. Baxter SD, Hardin JW, Guinn CH et al. (2009) Fourth-grade children's dietary recall accuracy is influenced by retention interval (target period and interview time). J Am Diet Assoc 109, 846-856.

28. Conway JM, Ingwersen LA, Vinyard BT et al. (2003) Effectiveness of the US Department of Agriculture 5-step multiple-pass method in assessing food intake in obese and nonobese women. Am J Clin Nutr 77, 1171-1178.

29. Conway JM, Ingwersen LA \& Moshfegh AJ (2004) Accuracy of dietary recall using the USDA five-step multiple-pass method in men: an observational validation study. J Am Diet Assoc 104, 595-603.

30. University of Minnesota Nutrition Coordinating Center (2014) Nutrition Data System for Research. http://www.ncc. umn.edu/ (accessed November 2015).

31. Hoelscher DM, Barroso CS, Springer A et al. (2009) Prevalence of self-reported activity and sedentary behaviors among 4th-, 8th-, and 11 th-grade Texas public school children: the school physical activity and nutrition study. J Phys Act Health 6, 535-547.

32. Hoelscher DM, Springer AE, Ranjit N et al. (2010) Reductions in child obesity among disadvantaged school children with community involvement: the Travis County CATCH Trial. Obesity (Silver Spring) 18, Suppl. 1, S36-S44.

33. Hoelscher DM, Day RS, Kelder SH et al. (2003) Reproducibility and validity of the secondary level School-Based Nutrition Monitoring student questionnaire. J Am Diet Assoc 103, 186-194.

34. Penkilo M, George GC \& Hoelscher DM (2008) Reproducibility of the school-based nutrition monitoring questionnaire among fourth-grade students in Texas. J Nutr Educ Behav 40, 20-27.

35. Centers for Disease Control and Prevention (2016) Youth Risk Behavior Surveillance System (YRBSS). https://www.cdc.gov/ healthyyouth/data/yrbs/ (accessed December 2016).

36. Laurent J, Catanzaro SJ, Joiner TE et al. (1999) A measure of positive and negative affect for children: scale development and preliminary validation. Psychol Assess 11, 326-338.

37. Joiner TE, Catanzaro SJ \& Laurent J (1996) Tripartite structure of positive and negative affect, depression, and anxiety in child and adolescent psychiatric inpatients. $J$ Abnorm Psychol 105, 401-409. 
38. Fitzgerald A, Heary C, Kelly C et al. (2013) Self-efficacy for healthy eating and peer support for unhealthy eating are associated with adolescents' food intake patterns. Appetite 63, 48-58.

39. Anderson Steeves E, Jones-Smith J, Hopkins L et al. (2016) Perceived social support from friends and parents for eating behavior and diet quality among low-income, urban, minority youth. J Nutr Educ Behav 48, 304-310.e1.

40. Banbury-Robinson J (1999) Ohio's 4H Cloverbud Program. Columbus, $\mathrm{OH}$ : The Ohio State University Extension.

41. Hans J \& McGaugh M (2013) Oklahoma CATCH Kids Club: 2011-2012 Analysis. https://www.ok.gov/health2/docu ments/2011-2012.pdf (accessed December 2014).

42. Sharpe EK, Forrester S \& Mandigo J (2011) Engaging community providers to create more active after-school environments: results from the Ontario CATCH Kids Club Implementation Project. J Phys Act Health 8, Suppl. 1, S26-S31.

43. Luton S \& Berry J (2011) CATCH Kids Club Healthy Habits \& Nutrition: An After-School Curriculum for Grades K-5. Hasbrouck Heights, NJ: FlagHouse, Inc.

44. Melnyk BM (2015) Creating Opportunities for Personal Empowerment: A 7-Session Cognitive Behavioral Skills Building Program for Children. COPE2Trive, LLC.

45. Hopkins LC, Rose A \& Gunther CW (2015) Camp NERF: Feasibility, Acceptability, and Potential Efficacy of a Theory-Based Nutrition Education Recreation and Fitness Program Aimed at Preventing Unhealthy Weight Gain in Disadvantaged Children during Summer Months. Boston, MA: Experimental Biology.

46. Hopkins LC, Rose A, Higgins E et al. (2015) Methods and Fidelity of a Nutrition Education Recreation and Fitness
Program to Prevent Child Weight Gain during Summer. Pittsburgh, PA: Society for Nutrition Education and Behavior.

47. Rubin DB (1987) Multiple Imputation for Nonresponse in Surveys. Wiley: New York.

48. Schafer JL (1997) Analysis of Incomplete Multivariate Data. Boca Raton, FL: Chapman \& Hall/CRC.

49. Centers for Disease Control and Prevention (2018) Exercise or Physical Activity. https://www.cdc.gov/nchs/fastats/ exercise.htm (accessed November 2018).

50. Janssen X, Mann KD, Basterfield L et al. (2016) Development of sedentary behavior across childhood and adolescence: longitudinal analysis of the Gateshead Millennium Study. Int J Behav Nutr Phys Act 13, 88.

51. Cooper AR, Goodman A, Page AS et al. (2015) Objectively measured physical activity and sedentary time in youth: the International Children's Accelerometry Database (ICAD). Int J Behav Nutr Phys Act 12, 113.

52. Kraemer HC, Mintz J, Noda A et al. (2006) Caution regarding the use of pilot studies to guide power calculations for study proposals. Arch Gen Psychiatry 63, 484-489.

53. Contento I, Balch G, Bronner Y et al. (1995) The effectiveness of nutrition education and implications for nutrition education policy, programs, and research: a review of research. J Nutr Educ 27, issue 6.

54. Katz DL, O'Connell M, Yeh M-C et al. (2005) Public health strategies for preventing and controlling overweight and obesity in school and worksite settings: a report on recommendations of the Task Force on Community Preventive Services. MMWR Recomm Rep 54, 1-12. 